of pasture research, hop research and tomato research at the Institute and of the chemical investigation on the constituents of the tobacco leaf responsible for variations in quality. Besides a list of publications, the report includes five short special articles. E. T. Chiltendon describes investigations on bitter pit in apples ; E. B. Kidson, chemical investigations on tomato plants in water culture; D. J. Stanton, further experiments on the treatment of tomato seedlings with $n$-m-tolylphthalamic acid; T. B. C. Christie, the effect of fertilizer applications on the Phytophthora disease of hops; and R. J. Monk, work on alkaloids and smoking quality of tobacco.

\section{The Brotherton Library, Leeds}

THE annual report of the Librarian of the University of Leeds, for the session 1959-60, records holdings at July 31,1960 , of 479,157 volumes and 179,215 pamphlets, of which 334,099 volumes and 117,306 pamphlets are in the Brotherton Library (Leeds: The Brotherton Library, The University. Pp. 12. 1960). Accessions during the year totalled 15,842 volumes, 3,281 pamphlets and 31,907 periodical parts. Loans to readers numbered 116,739 and inter-library loans 1,814 books borrowed and 3,449 lent. The report refers briefly to the extension of the Brotherton building proposed in the University Development Plan published in May 1960 which contemplates incorporation of an additional bookstack for 400,000 volumes, together with further reading rooms and larger administrative quarters, and a separate building for undergraduates with space for 800 readers and $30,000-50,000$ volumes. The proposals are being studied and, meanwhile, a further investigation of undergraduate use of library services is being made.

\section{Raw Materials of Ceramics}

IN The Museums Journal of March 1961, Mr. P. J. Adams describes an exhibition which was arranged to mark the occasion of the Seventh International Ceramic Congress and suitably modified will form a permanent feature at the Geological Survey and Museum, London. The exhibition is divided into three sections reflecting the main branches of the British ceramic industry: (1) pottery and whiteware; (2) structural clay-products; and (3) refractories and technical ceramies. Each section consists of a simple wall-type display with a single waist-high bench for the geological and ceramic specimens and a back-screen for narrative text, geologica] maps, photographs and diagrams. The nature, geological occurrence and methods of exploitation of the raw materials are briefly described and their processing and utilization are summarized.

\section{Selenium Poisoning}

Selentum poisoning is known to be a disease of domestic animals in the United States. Wheat, corn and milk produced in western and southern districts of the United States contain small quantities of selenium. Animal and vegetable foodstuffs from the United States make up an increasing part of the diet of Japanese school-children and this has led to investigations into experimentally produced selenium poisoning in various animals (Yokohama Med. Bull., 11, No. 5; October 1960). The investigations were carried out by Hiroshi Tsuzuki, Kazuhoshi Osawa and Takashi Hosoya of the Department of Hygiene,
Yokohama University School of Medicine, Yokohama, and showed that selenite had the greatest toxicity among animals. It disturbed the body weight, tibial length and physical strength of animals when it was given intraperitoneally and orally. Inhaled selenium vapour disturbed physical functions, but the toxicity varied because of varying degrees of selenium in the air. Metallic selenium, which was given orally, disturbed digestive functions temporarily and greatly influenced gain in weight and physical strength; it suppressed the development of tibial length only slightly. Selenium in ointment, rubbed on the skin of animals, caused a remarkable dermatitis, and a decreased gain in weight, but there was only slight suppression of tibial length and physical strength. Generally, females were more disturbed physiologically and developmentally than males. The second generations which were born from poisoned mothers seemed to have higher resistance to selenium than other animals.

\section{Internal Carotid Artery Occlusion}

Is recent years, internal carotid artery occlusion has been diagnosed frequently in young adults. A study by John G. Humphreys of the Department of Medicine, University of Toronto, and T. H. Newton, Department of Radiology, University of California, of seventeen patients of less than 40 years of age with carotid occlusion shows how the underlying mechanism accompanying the occlusion may differ from that in older patients in whom the cause is atherosclerosis (Brain, 83, Part IV; 1960). There were thirty-three older patients whose carotid occlusions occurred after the age of 40. There was little difference in the sex incidence of the younger group compared with the predominance of males in the older group. Eleven of the seventeen patients in the younger group either had lesions adjacent to the carotid artery or had evidence of a generalized systemic illness at the time the carotid occlusion was diagnosed. Four of the thirty-three patients of more than 40 years old had similar complicating factors. The complications of both groups included trauma, aneurysm, tumour, pregnancy, and inflammatory diseases. Hypertension, diabetes and atherosclerotic involvement of other major arteries were noted in only one of the seventeen younger patients, but were present in thirteen of the thirty-three older patients. The prognosis for survival following an internal carotid artery thrombosis is better in patients of less than 40 years of age.

\section{Dietary Fats and Cholesterol}

IN recent years the number of people dying from the sequelæ of vascular diseases has been as great in the Netherlands as highly industrialized countries. The influence of various dietary fats on the blood cholesterol content has been investigated by F. S. P. Van Buchem, J. J. Speelman, A. A. Idema, A. T. Valkema and $\mathrm{H}$. J. Thomasson, and is reported in the recent Proceedings of the Royal Netherlands Academy of Sciences (Series C. Biological and Medical Sciences, 44, No. 1; 1961). The twenty test subjects were physically healthy, were mentally defective and were constantly under clinical and dietetic supervision. Before the test diets were given, the spontaneous variations of the serum cholesterol-level of most test subjects were studied for several months. The test diets used only differ from normal diets in that different fats, but in the 